\title{
Characterizing mathematical problem solving in physics-related workplaces using epistemic games
}

\author{
Dehui Hu, Kingston Chen, Anne E. Leak, Nicholas T. Young, \\ Brianna Santangelo, and Benjamin M. Zwickl \\ School of Physics and Astronomy, Rochester Institute of Technology, \\ 84 Lomb Memorial Drive, Rochester, New York 14623, USA \\ Kelly Norris Martin \\ School of Communication, Rochester Institute of Technology, \\ 92 Lomb Memorial Drive, Rochester, New York 14623, USA
}

(Received 8 June 2018; revised manuscript received 16 May 2019; published 24 September 2019)

\begin{abstract}
In order to support physics students in their future careers, there is a need to understand the relationship between undergraduate education and professional practice in physics-related fields. This study investigated high-level goal driven mathematical problem-solving activities that are found within two disciplinary cultures: physical science research labs in academia and photonics workplaces in industry. We conducted semistructured interviews with $10 \mathrm{Ph} . \mathrm{D}$. students and 22 engineers and technicians. Math use in professional workplaces was characterized through an adaptation of epistemic games framework, which revealed six common epistemic games in these workplaces: conceptual math modeling, analyticalnumerical math modeling, design-oriented math modeling, fabrication, improving processes, and making meaning out of data games. The workplace-specific epistemic games capture the goals, starting and ending conditions, constraints and contextual features, moves, tools, and representations. The games involve a broad spectrum of math that ranges from arithmetic to computational modeling. The games reveal how goals and particular contextual features impact approaches to mathematical problem solving. The findings extend prior work on mathematical problem solving in physics to a new population of professional researchers, engineers, and technicians in their workplaces. The research may guide new approaches for developing problems and explicitly teaching problem solving in diverse physics contexts, which may additionally benefit undergraduate students' preparation for their future careers.
\end{abstract}

DOI: 10.1103/PhysRevPhysEducRes.15.020131

\section{INTRODUCTION}

Learning, and the impact of an education, continues long after students graduate from school and enter professional workplaces. Although there are many ways to frame a discussion about the intersection of education research and workforce development, two broad categories of work-related education research issues stand out: school to work as a critical educational transition and workplaces as science, technology, engineering, and mathematics (STEM) learning environments.

Focusing on the school-to-work transition enables us to understand how education supports the next generation of scientists and engineers. Further, it is important to learn

Published by the American Physical Society under the terms of the Creative Commons Attribution 4.0 International license. Further distribution of this work must maintain attribution to the author(s) and the published article's title, journal citation, and DOI. how students from diverse backgrounds make that transition in order to broaden participation in STEM careers. Although career preparation is just one of many reasons to support and improve STEM education (e.g., sparking curiosity, empowering citizens), STEM education is publicly valued because it is perceived as a path to goodpaying, future-oriented jobs for individuals and economic growth for communities and nations.

Examining the school-to-work transition is a natural extension of existing research on STEM career decision making, which includes investigations of the high schoolcollege transition. Prior research has shown that factors such as identity, self-efficacy, and outside of class science experiences may affect choice of major and persistence in STEM majors $[1,2]$. Some research has investigated outcomes such as career productivity [3], while other research has investigated trajectories of particular groups of people through case studies, such as black women physicists [4,5]. The relationship between work and school is sufficiently complex that it inspires lively debates about whether education is teaching generally applicable transferable 
skills, teaching "job-ready" specialized technical skills, or is mostly signaling attributes like dedication, the ability to receive instructions and meet expectation, and the ability to learn new things [6].

Workplace contexts also represent a relatively unexplored area for education research, and there is much for a curious education researcher to study. For example, the Adult Math Project revealed everyday settings involving "grocery store math" where the rich context of the problem strongly affected how arithmetic was employed, often in ways not taught in school [7]. We seek to understand similar questions about how the context of physics-intensive workplaces affects mathematical problem solving, particularly by comparing with classroom problem-solving practices, and how these may differ depending on contextual features of each environment.

Treating the workplace as a STEM learning environment is already a viewpoint embraced by the National Science Foundation [8]. Within physics it seems particularly important given the wide gap between typical faculty experiences and students' places of eventual employment. Although most courses in the undergraduate physics curriculum are consistent across institutions, physics majors diverge in many directions after completing a bachelors degree, including graduate school, software development, engineering, consulting, teaching, and other occupations not specifically linked to STEM [9].

Prior research on mathematical problem solving in everyday settings and workplaces provides surprising insights. Often workplace mathematics is so contextualized and situated with particular tools, ideas, and artifacts, that it is not even viewed as "doing math" by those engaged in the activity. Also, there are examples where competency in an everyday activity or work activity is clearly demonstrated, yet performance on related school math activities appears much lower [7]. Other unique aspects of math in workplaces include that math is often "black boxed" to streamline processes and reduce mistakes; however, uncovering math within the black box becomes essential when standard processes break down and need to be improved [10,11]. Additional differences in the workplace include problem types that are much more diverse, open-ended, and messy $[12,13]$.

Mathematical problem solving is a natural starting point for investigating workplace practices that overlap with typical goals for undergraduate physics education. There is a rich tradition of investigating mathematical problem solving as part of physics education research. Within the professional practice of physics, the role of mathematics is so essential it has been regarded as the "language of physics" [14] and its effectiveness at describing the physical world is so remarkable that one distinguished physicist described it as "unreasonable" [15].

Within this project, we delved into mathematical problem solving in physics workplaces through the use of in-depth interviews with engineers, technicians, and researchers. We employed epistemic games to guide our analysis of these workplace activities and then identified six particularly prevalent games that emerged from our data (fabrication, improving processes, answering questions with data, and three games involving modeling). The findings reveal games that are distinct from prior physics education research involving epistemic games, but still are relevant for supporting instruction in physics.

\section{BACKGROUND: PROBLEM SOLVING USING MATHEMATICS IN PHYSICS-RELATED CONTEXTS}

The physics education community has long been interested in studying the use of mathematics in physics problem solving. Across the undergraduate physics curriculum, there is a significant amount of research on problem solving using mathematics, including understanding the strategies employed by students, expert-novice differences on solving introductory problems, the development of problem-solving skills, as well as the transfer of problem-solving abilities [16,17]. However, there is limited research on how professionals solve physics problems using math as part of their research or other professional work, which may be distinct from solving textbook or school problems.

In this section, we review existing literature on the following topics: (A) What is a "problem"? And how do we define a problem? (B) How are mathematical tools used in undergraduate physics and workplace problem solving? And, (C) what common frameworks have been employed to understand students' use of mathematics in physics?

\section{A. Defining a problem}

Problem solving usually involves diverse processes that depend on the context and discipline. In order to study mathematical problem solving in physics-related workplaces, we need to define what we mean by "problems" in a workplace context and compare with the kinds of problems in a school context.

Hayes provided a useful general definition of a problem: whenever there is a gap between where you are now and where you want to be, and you don't know how to find a way to cross that gap, you have a problem [18]. Under this definition, there are three components that constitute a problem: the initial state, the goal state, and procedures to eliminate the gap between them [19]. The vast majority of end-of-chapter textbook problems fit this description. Those textbook problem are usually very well defined and very often, the three aspects can be explicitly identified.

Real-world tasks tend to be ill structured to various extents and they usually have ill-defined initial states where all information may not be known, ill-defined end goals, and many possible solution paths. To characterize the 
spectrum of problems, Jonassen [20] classified problems according to three attributes: structuredness (e.g., well structured vs ill structured), complexity, and domain specificity (i.e., domain and context specific). These three attributes inspired the development of a general typology of problems, including logical problems, algorithmic problems (e.g., most math problems), story problems (e.g., most end-of-the-chapter physics textbook problems), rule-using problems (problems that have clear goal or solution but multiple rules governing the process), decision making problems (selecting a single option from a set of alternatives based on a set of criteria), troubleshooting problems, diagnosis-solution problems, strategic performance problems (real-time, complex, and integrated activity structures), case analysis problems, design problems (ill structured with ambiguous specification of goals, no determined solution path, and the need to integrate multiple knowledge domains), and dilemmas (problems which involve social and/or ethical conflicts) [20]. This classification allows researchers to consider a broad spectrum of problems, from the well-defined, abstract questions in most textbooks to ill-structured, open-ended real-world problems in research labs, industrial workplaces, and everyday situations.

Later on, Jonassen and others studied problem-solving practices among professional engineers in Missouri, which happened to be mostly civil engineers [12]. His work was conceiving of problem solving more generally (e.g., everything from crossword puzzles to global warming) and he identified main attributes of workplace engineering problems, such as ill structured, conflicting goals, multiple solution methods, etc.

Hayes' definition also implies that not all tasks are problems and they becomes problems only when the individuals perceive them as problems. Adams and Wieman also pointed out that "the designation of a task as a problem must be based on the solver's response to the task, rather than the task itself. If a task does not qualify as a problem for a particular individual, then it becomes merely an exercise for them" (p. 459) [21]. More recently, Leak [13] expanded this definition and identified a framework to describe problems from the solver's perspective, which included three dimensions: contexts (e.g., setting up equipment, testing, and collecting data), activities (e.g., designing, troubleshooting, and assessing quality), and features of problems (e.g., limited resources, insufficient knowledge). This framework is particularly useful in characterizing problems beyond the undergraduate level.

Our study focuses on one class of problem solving activities (those that directly involve mathematics) as well as professional settings very likely to be encountered by physics graduates (e.g., optics and photonics companies as well as research labs). Those tasks are typically ill defined as they require the solvers to identify the problem (e.g., the end goal, constraints, and solution paths) using their own knowledge and skills. Our purpose is not only to identify the main characteristics of problems encountered in both industrial and academic workplaces, but also to categorize the common inquiry strategies used to solve those problems.

\section{B. Math use in physics-related problem solving}

Among the many aspects of problem solving in physicsrelated workplaces, we are particularly interested in the use of mathematics. Redish models the use of mathematics in physics as a process: mapping a physical situation onto a mathematical model, processing mathematical representations, interpreting mathematical results in physics, and evaluating whether the results adequately describe the physical system [22].

Regarding the use of mathematics in school physics contexts, a number of studies have shown that students are rather proficient at mathematical operations; however, they have difficulties developing mathematical models based on physical situations and dealing with a variety of mathematical representations, such as vectors [23-25], the coordinate system [26], and graphs [27].

Prior research implied that there are systematic differences between mathematics in the workplace and in traditional classroom teaching. First of all, context is crucial to the mathematics practices in the workplace. The kinds of representations (e.g., symbols, tables, and graphs) used in workplaces are different from the ones in a school context. Workplace activity with mathematics often relies on relatively simple mathematics embedded in complex situations. In Wake's study, students failed to apply the concept of slopes to a routine task that a railway operator would have to solve. The difficultly largely arose from the differing conventions and notations used in industry and math education [11]. In Triantafillou's study, a group of telecommunication technicians worked to find a fault in their local wiring network and their usage of the place value concept was studied. Cognitive difficulties arose when the technicians had to link two different notational systems: the arithmetic representation in school system and the concrete representation of the place value system in the cable closet (i.e., the location in the patch board represents the "unit," the patch board represents the "ten," and the ten-patch boards together represent the "hundred") [28]. The use of industrial-specific metaphors and mathematical models in workplace can lead to a disconnect between school and workplace math use [10].

Second, mathematical processes are often disguised by tools in workplace cultures $[10,29]$. Through a case study of visits by college students and teacher researchers to workplaces, William and Wake [10] concluded that mathematical processes are hidden by instruments, rules, and divisions of labor in workplace cultures. The use of automation processes tends to hide mathematical work and at the same time evolves a distinct workplace genre of mathematical practice. Modern computer technology also 
hides the use of mathematics in the software and mathematics as a tool fades to the background in many workplace routines [30].

As technology has transformed our lives tremendously, the ability to use computers to solve problems is becoming a fundamental skill in science, education, and workplaces. Wing defined computational thinking as "the thought process involved in formulating a problem and expressing its solution(s) in such a way that a computer human or machine can effectively carry out [31]." Computational thinking has already influenced the learning and research of all science and engineering disciplines. Weintrop et al. further proposed a taxonomy of computational thinking consisting of four main categories: data practices, modeling, and simulation practices, computational problemsolving practices, and systems thinking practices [32]. When solving physics problems in workplaces, it is essential to utilize computational tools to incorporate the various real world constraints and complexity into numerical solutions. Increasingly, computational tools and software are employed to solve real world problems, such as MATLAB for conducting numerical calculations and visualizations, or ZEMAX for optical design. More recently, research in math, physics, and science education has focused attention on the development of computational thinking skills in the undergraduate curriculum [31-34] and even high school science classes [35].

While prior research explored the differences between school math and workplace math within a few particular fields, our study involves workplaces more closely related to physics, such as research labs in the physical sciences and companies in optics and photonics. In addition, the workplace environment also provides a perfect opportunity to learn how mathematical representations and computational tools are used in professional settings.

\section{Frameworks about math use in physics problem solving}

To understand math use in physics-related workplaces, we need a framework to help organize the various inquiry strategies used by professionals. We provide an overview of several existing frameworks for describing mathematical thinking and behaviors, along with an explanation of our decision to use epistemic games to guide our analysis. The common frameworks include mathematical resources associated with symbols and equations (i.e., symbolic forms) [36], conceptual blending [37,38], epistemic games [17], and epistemological framing $[17,17,39,40]$.

Through exposure to formal mathematical expressions in math courses and in courses that apply math, students not only learn the rules of how to perform calculations, but also develop a sense of mathematical notation and equations [36]. Symbolic forms, which are also called cognitive mathematical primitives, allow students to associate meanings with certain structures of mathematical expressions.
A symbolic form has two components: a symbolic template [e.g., [] = [], ([])/([]) where the boxes can contain any type of mathematical expression] and a conceptual schema. The conceptual schema is a simple structure associated with the symbolic form that offers a conceptualization of the knowledge contained in the mathematical expression [36]. The symbolic forms framework was targeted at the sense making of mathematical equations.

The conceptual blending framework (also called mental space integration framework) focused on the interplay between knowledge stored in different mental spaces [41]. To characterize how students apply mathematics in physics problem solving, several prior studies explored the ways students integrated their math and physics knowledge. Bing and Redish described two representative ways in which students blend their knowledge from physics and mathematics mental spaces: a single-scope blend (i.e., a one-way mapping of physical quantities to an existing mathematical equation or template) and a double-scope blend (i.e., an integration of an existing mathematical equation and a physical scenario) [37]. $\mathrm{Hu}$ and Rebello identified four different types of blends when observing students' application of calculus integration concepts in solving physics problems, with two blends relying heavily on algebraic manipulations, one involving a unidirectional mapping of physical quantities to the structure of an existing equation, and the fourth emphasizing the integration of knowledge in several mental spaces [38]. The conceptual blending framework is very useful in understanding and modeling students' behaviors in solving physics problems using specific mathematical concepts and tools.

Problem solving is a dynamic process and the context often has a huge impact on how students frame and approach a problem. Several studies looked at the issues of epistemological framing on mathematical problem solving in physics. When solving physics problems, a student may frame a physics problem as an opportunity for making sense of the concepts or an occasion for manipulating formulas and numbers [42]. By identifying the warrants involved in their problem solving, researchers can get information about students' tacit epistemological resources that are activated in their mind [17,39,40,43].

Tuminaro and Redish [17] adapted the idea of epistemic games to describe the overall strategies that students employ during their mathematical problem solving in physics. An epistemic game is defined as a complex "set of rules and strategies that guide inquiry [44]." Tuminaro and Redish defined six epistemic games that describe the use of math in introductory physics problem solving. A comprehensive review of the epistemic games framework is provided in the next section.

In order to categorize common strategies used in workplace mathematical problem solving, we need a framework to characterize how professionals coordinate various kinds of resources (e.g., knowledge resources, constraints, and 
contextual factors) in a complex environment. Epistemic games nicely capture how individuals respond to a specific problem-solving environment in terms of when to start an e-game, what moves to make, and what kind of representations to follow. The symbolic form framework is more useful in making sense of specific mathematical symbols and equations but not the overall strategies during the problem-solving process.

\section{FRAMEWORK: EPISTEMIC GAMES}

\section{A. Introducing epistemic games}

To understand how individuals organize different kinds of knowledge resources to solve physics problems, we adapted epistemic games introduced by Collins and Ferguson [44]. Collins and Ferguson define an epistemic game as "a complex set of rules, strategies, and moves associated with particular representations (i.e., epistemic forms)." They introduce the idea of epistemic games to describe expert scientific inquiry across disciplines. The games are epistemic in the sense that they are played for the construction of new knowledge and sense making of a phenomenon in the world. Tuminaro and Redish [17] then extended this framework to describe students' problem solving in introductory physics courses. According to Tuminaro and Redish, an epistemic game is defined as "a coherent activity that uses particular kinds of knowledge and processes associated with that knowledge to create knowledge or solve a problem." The idea of epistemic games refers to a locally coherent set of rules that are directed toward a particular goal, which is creating knowledge or solving problems.

By synthesizing the prior research that utilized epistemic games, we summarize the primary characteristics of epistemic games in Table I, which are the epistemic form, entry and ending conditions, moves, constraints and other contextual features, and knowledge base $[17,44,45]$. The epistemic form is often an external representation that helps guide inquiry during an epistemic game. For example, Collins and Ferguson describe the list making game, which is one of the basic epistemic games used in everyday situations (e.g., "What do I need from the grocery store?")

TABLE I. Characteristics of epistemic games.

\begin{tabular}{lc}
\hline \hline Epistemic form & $\begin{array}{c}\text { External representations that guide } \\
\text { inquiry } \\
\text { Conditions for when to begin and } \\
\text { end a game } \\
\text { conditions } \\
\text { Moves }\end{array}$ \\
$\begin{array}{c}\text { Actions that can be taken at different } \\
\text { points in the game } \\
\text { Constraints and other } \\
\text { Factors that influence actions and } \\
\text { decision-making in the game } \\
\text { (e.g., rules, tools, and cost) }\end{array}$ \\
$\begin{array}{c}\text { Knowledge base } \\
\text { collection of knowledge resources } \\
\text { associated with the game }\end{array}$ \\
\hline \hline
\end{tabular}

as well as in scientific inquiry (e.g., "What are different forces in the world?") [44]. In the list making game, the epistemic form is the list itself and list is an external representation that guides the progression of the game. It is also possible that several representations might exist to guide the inquiry so there may be more than one epistemic form during an epistemic game.

The entry condition determines when to start a particular game. It is not only determined by the external stimuli (e.g., a question or request) and resources available to the problem solver, but also strongly affected by the problem solver's expectations about the problem context. In the list making game, the question "What are different forces in the world?" may motive an individual to start the game. The moves of an epistemic game are the steps or procedures that occur in the game. The possible moves of the list making games are to add a new item, combine items, substitute an item, split an item, and remove an item [44].

Constraints are the rules of the game, imposed by the problem context or the problem solver. In the list making game, distinctness could be one of the constraints and it requires that no two items overlap or are difficult to distinguish. When solving physics problems, the problem solver may impose one or more constraints by making certain assumptions or approximations (e.g., ignoring air resistance or applying a conservation law). Here, an epistemic game may also be constrained by other contextual features, such as time or resources.

Knowledge base is a collection of knowledge resources an individual activates when playing an epistemic game, and it is also the prerequisite knowledge to play an epistemic game. For instance, to answer the question "What are the forces in the world" the individual needs to have a basic knowledge of what a force is.

\section{B. Identification and application of epistemic games}

We will now review studies that adapted epistemic games as well as some of useful epistemic games identified in prior work. Collins and Ferguson first introduced epistemic games and then defined a set of basic epistemic games that are useful in everyday, scientific, and social contexts, such as the compare and contrast game [44]. The epistemic games defined in Collins and Ferguson's work are based on experts' inquiry strategy. Later on, several studies extended epistemic games framework to describe students' problem-solving behavior in a variety of contexts.

Tuminaro and Redish identified six epistemic games that describe different problem-solving strategies observed among introductory algebra-based physics students as they were problem solving [17]. To identify these epistemic games, Tuminaro and Redish looked for coherent activities or routines that the students engaged in for the purpose of solving a problem or creating knowledge. Those six epistemic games are mapping meaning to mathematics, mapping mathematics to meaning, physical mechanism, 
pictorial analysis, recursive plug and chug, and transliteration to mathematics.

Gire et al. identified a graphical analysis epistemic game that characterizes students' use of graphs in introductory physics courses [46]. The study found that one particular move, which they called create a story, was the most difficult for students, both in terms of connecting the graph to the physical situation and connecting the graph to concepts. Additionally, they also analyzed the role of hints as students played epistemic games. For example, the study found that encouraging students to provide information about the connection between the graph and the physical situation enabled them to make a correct move and led to a productive understanding of the problem.

Chen et al. identified the answer-making epistemic game when evaluating students' learning of hydrostatics [47]. The goal of the answer-making game is to select an answer to a multiple-choice problem and have some justification or reasoning for the answer. Within this game, two alternate paths were identified: the answer-justification path (answer based on memory leads to justification which reassures the answer), and reasoning-answer path (the answer is arrived through the reasoning, not memorization). Chen et al. argued that both the problem and students' level of confidence significantly affect students' reasoning and the moves they make. They also pointed out that the answer-making epistemic game is a larger scale game which may help students coordinate which subgames to play.

Bajracharya and Thompson adapted epistemic games to analyze how students derive equations using symbolic manipulations and routine mathematical operations (i.e., procedural resources) in the context of solving problems involving temperature or electrostatics [45]. While observing introductory physics students solving problems that were rich in algebraic and graphical representations, they documented another specific epistemic game (i.e., analytical derivation epistemic game). They pointed out that the analytical derivation game is necessary to solve the physics problems; however, it is not sufficient because problem solving also requires students to meaningfully interpret the results of a derivation.

More recently, Sevian and Couture used epistemic games to characterize students' strategies for solving a variety of substance characterization problems in first-year chemistry, organic chemistry, and physical chemistry courses [48]. They collected data from individual student interviews and identified five epistemic games: compare, contrast, prototype mapping, inference, and model-based reasoning. They also categorized the epistemological framing (e.g., doing a lesson vs doing science) and discussed how the epistemological framing affected epistemic games played. For example, in the model-based reasoning game, students who chose a "doing the science" frame would use information from the problem as parameters or conditions that constrain the applicability of a model. In contrast, when choosing a less productive "doing the lesson" frame, students would apply models as rules. Thus, students' expectations about the activity play an important role in the epistemic games played.

In our research, we found that context plays an important role in choosing and playing epistemic games. In order to articulate the relevant context more fully, we sought inspiration from cultural-historical activity theory, which describes real life activities (e.g., problem solving) of individuals as they interact in a particular setting with particular goals and tools [49]. Wake [11] used culturalhistorical activity theory to identify schools and workplaces as activity systems that evolve both culturally and historically, with actions of the individual contributing to activities of community in pursuit of goals and outcomes. Thus, the cultural-historical activity theory nicely captured how individuals use tools to achieve goal-driven activities in a particular activity system. In order to capture the impact of contextual features, especially related to the culture of the work environment, we extended the "constraints" of epistemic games to "constraints and other contextual features," which involves multiple facets, such as the problem feature, external resources, motivation of the problem solver, and social environment. Hence, one of the goals of our study is to clarify and categorize the various kinds of factors that might influence the actions in playing epistemic games.

\section{METHODOLOGY}

\section{A. Data collection}

Our participants included Ph.D. students working towards their doctoral degrees and employees in the optics and photonics industry. The Ph.D. research data included $375 \mathrm{~min}$ of audio-recorded interviews with $10 \mathrm{Ph} . \mathrm{D}$. students at a private, doctoral granting university with moderate research activity in the northeast United States. This sample included 5 men and 5 women. The dissertation fields included astronomy, astrophysics, optics, imaging, semiconductors, and device physics. The students' research projects included computational, experimental, and observational methods. Interviews were semistructured and followed a protocol that first explored a student's dissertation project and then later focused on instances of analytical and computational mathematics that were present in their research. Interviewees were asked to describe the difficult, important, and routine tasks they performed in their projects that included analytical math. Further questions explored how each student proceeded to solve these tasks. After discussing analytical math, the interviewee was asked the same questions but regarding their use of computational math.

The photonics workplace data included $1345 \mathrm{~min}$ of interviews conducted with 13 managers, 5 engineers, and 5 technicians from 13 different companies that are a part of 
the optics and photonics industry in the Rochester, NY region. Managers oversaw technical projects and the personnel carrying out those projects. Managers came from diverse backgrounds, including optics, physics, and engineering (mechanical engineering, chemical engineering). Most of them had a bachelor's degree and only two had a $\mathrm{Ph} . \mathrm{D}$. degree. Engineers were individuals responsible for the design of products. Four of the five engineers had a Master's degree and one had a bachelor's degree. Their undergraduate programs included applied math with finance, physics and philosophy, optics, mechanical engineering, and optical engineering. The technicians were individuals responsible for the manufacturing of the products. The technicians were all high school graduates with some college education. All job titles come from selfidentification about their roles. The engineers and technicians were recent hires who had been in their current positions for less than two years. The interview protocol used for the engineers and technicians addressed their background information, general competencies that they believed were important or useful in their workplace, and then delved into particular situations or activities in the workplace where mathematics played a significant role. The interview audio files were then sent to a third party transcription service and the transcripts were then used for coding and further analysis.

The best way to identify epistemic games is to observe participants as they work. However, due to the nature of the participants and their types of projects, it is very difficult to collect real-time data of their problem-solving activities. Given the length of projects conducted by $\mathrm{PhD}$ students and the privacy concerns of industrial employers, it is challenging to observe participants in the act of problem solving. Also, considering the time constraints of participants, it is more feasible to conduct individual interviews that reflect on workplace experiences.

\section{B. Data analysis}

The coding process took several steps.

Step 1: Develop a coding dictionary. We first went through all transcripts and highlighted all instances of math usage seen. These instances were then combined in a word document and assigned descriptions as to how math was used in each instance. Instances that shared similar descriptions of how math was used were grouped together, which results in emergent themes of the different types of math usage (e.g., computational modeling and simulations). Interrater agreement was checked by having all interviews coded by more than one person. Discussions among coders often addressed the underlying math behind each code. For example, if an instance of modeling a physical system was coded, we would discuss how each of us interpreted that task. What math topics were applied for the modeling? Can this be grouped with other modeling instances? If there were disagreements, each coder would first present their argument to the group as to why they believed that an instance is best coded as a particular code. After hearing each idea, we would go back to the interview transcript and read around the coded instance to establish a context for the code. The emergent coding was revised until agreement was reached and after that, the emergent themes were incorporated into a coding dictionary. Separate coding dictionaries were created for Ph.D. research and industry interview data.

Step 2: Code transcripts using NVivo. All transcribed interviews and revised codes were imported into QSR International's NVivo 11 qualitative data analysis software. Subsets of source text were coded using the coding dictionary. This allowed us to confirm emergent codes and conduct additional analyses.

Step 3: Identify math activities and processes. The emergent themes of math use in both disciplinary cultures were categorized as either a math activity (e.g., more situated within a particular context and goal) or a math process (e.g., more procedural). For example, one of the goal-driven math activities identified in Ph.D. research was modeling and the more procedural math processes involved in this modeling activity were exploring simplified models, expressing models as equations, understanding the impact of parameters, extending analytical models with realism and complexity, and expressing models using codes and simulations. A goal-driven math activity often consisted of a series of math processes. Epistemic games allowed us to view each of these activities and processes as part of socially embedded epistemic games.

Step 4: Check coherence of math activities and processes. When coherent units of math processes seem to appear in a variety of contexts and interviews, they were integrated into a single epistemic game. The corresponding math activities were identified as epistemic games. We identified six major epistemic games that represented most of the key features of the problem-solving behaviors in our data.

Step 5: Identify characteristics of epistemic games. Those identified epistemic games in the previous step were discussed among the authors. More specifically, we systematically identified the characteristics of each epistemic game shown in Table I: epistemic form, entry and ending conditions, moves, constraints and other contextual features, and knowledge base.

The epistemic games and example quotes are presented and discussed in details in Sec. V.

\section{RESULTS}

In this section we discuss six epistemic games that emerged from our data. There are three types of modeling games (Secs. VA, V B, and V C), which are also summarized in Table II, the fabrication game (Sec. V D), improving processes game (Sec. V E), and making meaning out of data game (Sec. V F). Those six epistemic games are not a 
TABLE II. An overview of the three modeling games.

\begin{tabular}{|c|c|c|c|}
\hline $\begin{array}{l}\text { Modeling } \\
\text { e-games }\end{array}$ & Conceptual math modeling & Analytical-numerical math modeling & $\begin{array}{l}\text { Design-oriented math } \\
\text { modeling }\end{array}$ \\
\hline Goals & $\begin{array}{l}\text { To conceptually understand } \\
\text { a physical system or } \\
\text { situation }\end{array}$ & $\begin{array}{l}\text { To develop a full understanding and } \\
\text { solution to a problem with } \\
\text { real world complexity }\end{array}$ & $\begin{array}{l}\text { To design an object based } \\
\text { on specific requirements }\end{array}$ \\
\hline Epistemic forms & $\begin{array}{l}\text { Symbolic equations, verbal, } \\
\text { or schematic representations }\end{array}$ & $\begin{array}{l}\text { Symbolic equations, } \\
\text { algorithms, or graphs }\end{array}$ & $\begin{array}{l}\text { Symbolic equations, software, } \\
\text { and schematic representations }\end{array}$ \\
\hline $\begin{array}{l}\text { Constraints and } \\
\text { other contextual } \\
\text { features }\end{array}$ & $\begin{array}{l}\text { Qualitative sense-making } \\
\text { of a physical system }\end{array}$ & Relying on computational tools. & $\begin{array}{l}\text { Customer needs and other } \\
\text { factors, such as time, } \\
\text { cost, and materials. }\end{array}$ \\
\hline $\begin{array}{l}\text { Unique } \\
\text { features }\end{array}$ & $\begin{array}{l}\text { Focusing on a conceptual, } \\
\text { qualitative understanding } \\
\text { of a physical situation }\end{array}$ & $\begin{array}{l}\text { Focusing on both conceptual and } \\
\text { quantitative solutions, typically } \\
\text { involving the extension of an analytical } \\
\text { model to a computational model }\end{array}$ & $\begin{array}{l}\text { Focusing on modeling a } \\
\text { fabricable object based } \\
\text { on its required function }\end{array}$ \\
\hline
\end{tabular}

complete list of all games that involve the use of math in research or industrial settings; however, they represented most of the mathematical problem-solving behaviors in our data. For each game, we discuss the entry and ending conditions, moves, typical knowledge base, and epistemic forms associated with the moves. Then, we present excerpts from our data to demonstrate how each game helps to describe mathematical problem-solving approaches in a variety of settings. We present between two and four examples for each epistemic game depending on how many were needed to illustrate the moves and representations in a game. In order to visually simplify the sequence of moves in a game, we have presented Figs. 1-6, as linear processes; however, iteration is likely to occur in all of the epistemic games and was sometimes mentioned during the interviews.

\section{A. Conceptual math modeling game}

The conceptual math modeling game is typically played when there is a need for qualitative sense making about a physical system or situation. It is usually a quick process without considering many details or real-world constraints. The goal of this game is to develop mechanistic explanations by building a conceptual model rather than numerical predictions.

The conceptual math modeling game is shown in Fig. 1. The ending condition is a qualitative description of the mechanisms and behaviors of the physical system. Five moves were identified: (i) comprehend the real-world problem, (ii) identify underlying principles, (iii) express models using analytical math, (iv) understand the impact of parameters, (v) explain mechanisms and behaviors of the system using models. The knowledge base associated with the first two moves consists of the fundamental concepts and underlying principles related to the real-world problem. The next important move is to write the underlying principles in a mathematical form so that the player can relate the variables and parameters to the real world context and understand the impact of parameters. This move not only requires mathematical skills to interpret a relation between different variables, but also math manipulations that describe what happens to the physical system when a

\section{Conceptual Math Modeling Game}

Knowledge base: knowledge about physics context and theories; mathematical skills, such as trig, calculus, and basic arithmetic.

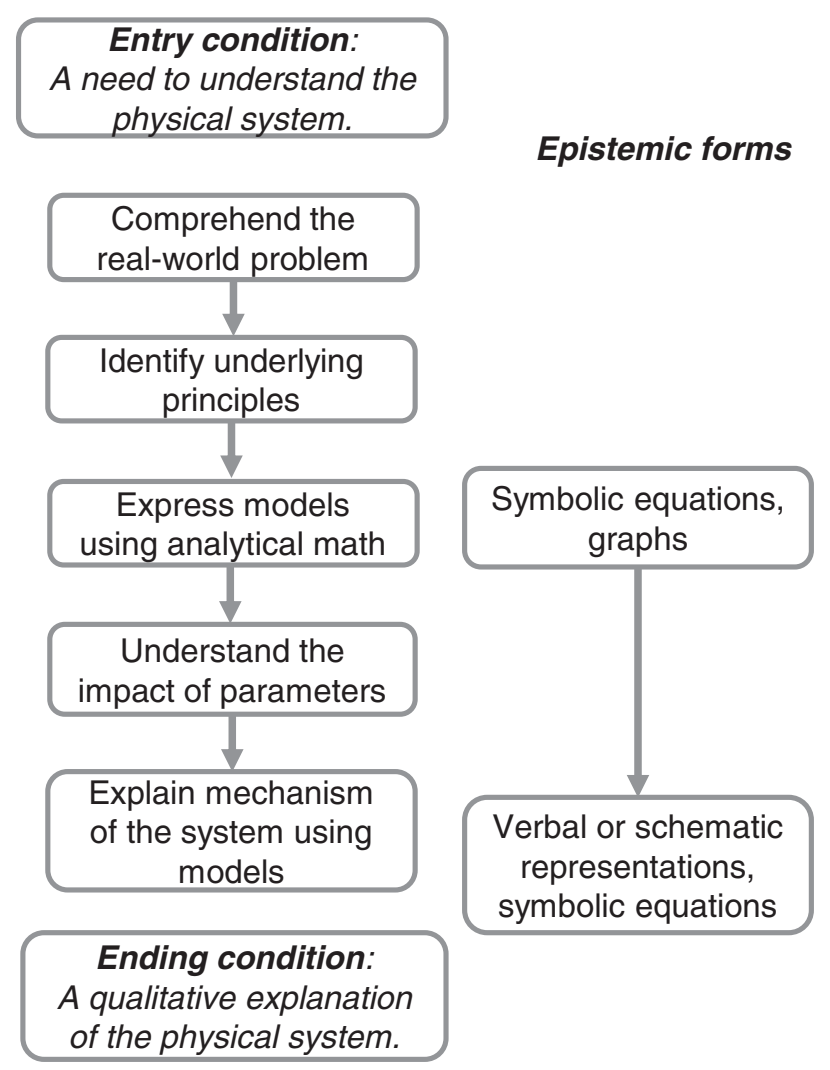

FIG. 1. Conceptual math modeling game. While process is shown linearly, iteration commonly occurs between steps. 
variable changes. Finally, a coherent conceptual explanation is created to describe the mechanism and behavior of the physical system using mathematical models, which also indicates the end of the modeling game.

When playing this game, the epistemic form typically involves a collection of mathematical equations or graphs that is activated by the player during the move express models using analytical math; then, during the last move, the epistemic form usually transitions to a verbal, schematic, or symbolic representation depending on the physical system as well as the preference of the individual.

We now illustrate how the conceptual math modeling game is played in research labs or industrial workplaces. Because our interview data are based on interviewees' reflections about their past activities regarding the use of math in their projects, the quotes from one episode might not reflect all aspect of an epistemic game.

\section{Example of the conceptual math modeling game (A)}

A $\mathrm{Ph} . \mathrm{D}$. researcher described how analytical math supports developing an intuitive qualitative understanding about a key system in his research project, which dealt with a highly sensitive force measurement. The player also discussed how analytical math makes it easier to understand the impact of parameters on the behavior.

"So, the purpose where I use analytic math would be to get a first order intuitive understanding of the system. And in special cases, that's all that's necessary. The system can be fully described by the analytic expression."

"And in those cases where it's much easier to dive into the impact of parameters, understanding the impact of parameters when you have an analytical expression. So that's always my first go to when I'm trying to understand a system."

The researcher went on to demonstrate how that general process was specifically applied in his research. First, he discussed the underlying principles and concepts (e.g., force, torque, and torsion balance). Then the system (a torsion balance) was modeled by an analytical expression, such as series of masses separated by springs. The analytical expression was used to explore how the behavior was affected by each parameter (e.g., mass, moment of inertia). The desired ending condition is a conceptual model based on fundamental principles that predicts particular trends, rather than specific numerical answers.

"The study that I'm doing right now involves these micro torsion balances and I'm applying a force-a torque - to the balance and I want to know how the balance moves under this force... Well the first order approximation of the system is to say that the torsion balance is a simple series of masses separated by springs, and in using that analytical model I can get full expressions of the system and understand the impact of, say, knowing the exact mass of each mass, or the moment of inertia, these components, or the spring constant of the springs. And I can understand which mass is more important to know precisely....things of that nature."

The industrial workplace also provides rich context for the use of math for a qualitative sense making of a physical system. Below is a simple example of a workplace scenario that requires the conceptual math modeling game.

\section{Example of the conceptual math modeling game (B)}

A manager of optical technicians described a typical optics problem encountered in the workplace that requires a quick qualitative understanding.

"It's for the conceptual understanding of how optics works. If I've got a lazy asphere vs a steep asphere, this is what happens to the light. This is the difference in angular outputs. So, then they have an understanding based on the geometry that they have to review, and potentially the profilometry traces of these parts. Then, conceptually, they can say, 'Okay, I have a weak asphere because my geometry's dipped down a little bit here, that's why my light's taken off.',

"It's the understanding of light and movement and how that works, that is the foundation for where and how intense I have to train people."

The manager discussed the need for developing a conceptual understanding for aspherical lenses. It starts with the lens system, and then one must be able to identify the underlying principle of how light travels through lenses. More specifically, it is important to know how the surface shape affects the output light. It is also common to include diagrams or symbols to facilitate the explanation. The technicians did not pursue detailed calculations in this particular situation; instead, they used existing models to form a general qualitative understanding of how aspherical lenses work.

Overall, the conceptual math modeling game is played often in both academia and industry. In workplaces, professionals often need to develop a quick conceptual understanding of a real-time situation and sometimes communicate with their collaborators or peers about their understanding, reminiscent of Alan Schoenfeld's description of math as a social activity of engaging in sense making [50].

\section{B. Analytical-numerical math modeling game}

The analytical-numerical math modeling game is usually triggered by the need to solve a complex real-world problem, which is often difficult to analyze and find an 


\section{Analytical-numerical Math Modeling Game}

Knowledge base: Context-specific concepts and principles; mathematical skills, such as algebra, calculus, differential equations, discrete math, and numerical skills.

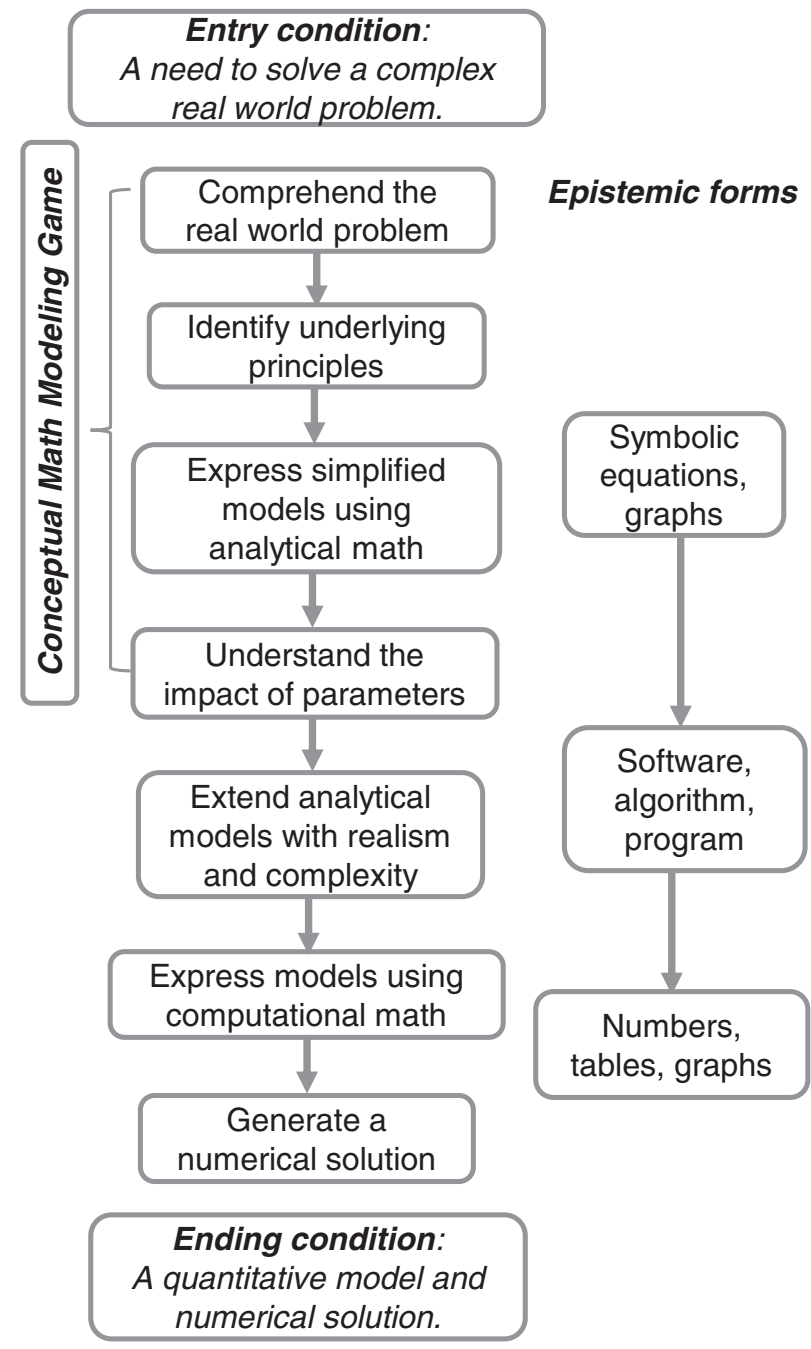

FIG. 2. Analytical-numerical math modeling game. While process is shown linearly, iteration commonly occurs between steps.

exact solution, typically requiring computational tools as part of the solution. The game begins by the conceptual math modeling game, which is a subgame within the larger game; however, the eventual goal of this game is to obtain a solution to a more realistic and complex problem.

The analytical-numerical math modeling game is shown in Fig. 2. The ending condition is a quantitative model and a numerical solution. Seven moves are identified: (i) comprehend the real world problem, (ii) identify underlying principles, (iii) express simplified models using analytical math, (iv) understand the impact of parameters, (v) extend analytical models with realism and complexity, (vi) express models using computational math, (vii) generate a numerical solution. The first four moves can be considered a subgame with a subgoal to develop a conceptual understanding of the physical system using a simplified analytical model. However, the ultimate goal of the game is the extension of the simplified analytical model to a more accurate and realistic numerical solution, which occurs in the final three steps.

In order to solve a complex real-world problem, the player needs to comprehend the real-world situation, and then simplifies the physical situation by creating a simplified analytical model. Employing a simplified analytical model aids in understanding the complex problem and in exploring a holistic solution. In the simplified situation, the player can use the simplified model to make sense of the physical process and understand the impact of parameters on the system. Since the simplified model is usually expressed in analytical math, the epistemic forms consist of mathematical equations and/or graphs, which often provide an alternative way to find a solution.

The next important move is to extend the existing simplified model with realism and complexity based on the specific situations of the problem. It is usually impossible to implement the complex model using only analytical math; thus, it is necessary to utilize computational tools to solve the problem numerically. A complete model of the physical system is usually expressed in equations and algorithms. The solution is explored through simulations, which often produce an output in the form of numbers, tables, or graphs. Hence, the epistemic forms include equations, algorithms, symbols, and graphs. The game ends with a quantitative model with a numerical solution.

The knowledge base of this modeling game includes context-specific concepts and principles, as well as mathematical skills. From our interviews, the mathematical skills include algebra, calculus, differential equations, discrete math, and computational skills. The computational skills depend on the specific problem, and may include using a specialized simulation software (e.g., ZEMAX for optical system modeling), or general purpose programming tools (e.g., MATLAB). This game was played mostly by $\mathrm{Ph} . \mathrm{D}$. researchers when working on a complex research project.

\section{Example of the analytical-numerical math modeling game (A)}

The same researcher as shown in example A of the conceptual math modeling game (Sec. VA) continued to discuss the use of computational math after first employing a qualitative understanding of the torsion balance system. The quotes focus on the transition from the conceptual model to the computational model, which involves the last three moves of the game.

"So it [the model] gives me a better understanding of my system so that when I take it to the next step-a 
simulation-based step using finite elements analysisthen I don't have to sweep across the entire parameter space."

The researcher then explained the process of extending a simplified analytical model to a computational model. According to the player, the development of the computational model is often an iterative checking and revision process.

"The analytic model, understanding the spring constant, reducing it down to a spring constant for a bar, like think of it as a steel bar or something like that if you're twisting a steel bar... So, I solved the spring, I got a number-a value-for the spring constant using my analytic expressions, then I did the finite element modeling of the system and said, 'Wow, it's totally different.' Went back and fine-tuned, figured out what was wrong with how I put together my analytic expression, and I realized that my moments of inertia were actually way off the what I'd predicted them to be where I wasn't calculating it well."

Later on, the researcher came back to emphasize the goal of the game, which is to get the oscillation frequency. The analytical model allows for a prediction of the system behavior (i.e., estimating the harmonic modes frequencies), while the computational model (i.e., finite element modeling) provides an accurate numerical prediction.

"Well, an experiment that I'm working on right now, actually the most important computational element is in the finite element modeling of this physical system. Getting back to that torsion balance, I have the analytics expression, which is nice to know and it gives me a ball park. But really what I need to know is the oscillation frequency so that when I'm physically in the lab measuring these things, I'm not looking all over the place, I have an idea of what are my harmonic modes. So I would say using very extensive computational programs, whether they're already built or not."

This epistemic game ends with a complete computational model and a numerical solution, which is often expressed as numbers, tables, or graphs.

\section{Example of the analytical-numerical math modeling game $(B)$}

Another Ph.D. researcher discussed the process of modeling a complex optical instrument. The first step is to look for a simpler instrument that they can easily handle analytically which corresponds to the move "explore simplified analytical models." With a simplified model (e.g., a circular aperture), she was able to work out the theory in pencil and paper (i.e., express simplified models using analytical math).
"Typically, we can do diffraction calculations in pencil and paper in simple cases. So, a lot of times, we'll design an instrument for a simple aperture, like a circular aperture, and usually these are easy to handle analytically."

The simplified model also makes it possible to understand the impact of parameters in a simplified system and the basic physics concepts can be extended to a more complicated system. Then the next step is to use the basic ideas they learned to design a complicated system by adding more real world complexity and constraints, such as secondary mirrors in telescopes. It is often impossible to express the complete model with analytical math, so it is necessary to use computational tools.

"And then we apply those ideas-the basic ideas-to more complicated systems. So, many telescopes nowadays have secondary mirrors and spiders and segments, and it's really hard to describe those systems analytically. And so, then we move on to just numerical mathematics, to the more specific cases."

The analytical-numerical math modeling game appeared quite frequently in research projects, which suggests it is critical for physics majors to develop the analytical and computational model building skills that will help them solve real-world complex problems. For common problems in research faced by scientists and engineers there may be specialized software dedicated to that problem (e.g., optical system design). However, research is often focused on solving problems with unique elements that require solutions beyond the standard toolbox, which requires the development of new algorithms and code scripts dedicated to that particular problem.

\section{Design-oriented math modeling game}

The design-oriented math modeling game is played when there is a need to design a physical object based on specific requirements (e.g., function, size, ruggedness, specific mechanical or optical specifications). Unlike the other two modeling games, which focus on understanding how a physical system works, this modeling game focuses on developing a model of a real object which may not exist yet, but needs to be manufactured in way that satisfies a customer's needs. It requires a different set of skills and strategies to play this game as will be discussed further below.

The design-oriented math modeling game is shown in Fig. 3. The ending condition is the creation of a design (e.g., print or blueprint) of a manufacturable product, which will often lead to fabrication and further testing. As one engineer we interviewed stated, "You can't build anything without prints. That is the work product of what we [engineers] make here. There's not a meeting you have 
Design-oriented Math Modeling Game

Knowledge base: knowledge about physics context and theories; mathematical skills; other professional skills, such as being able to visualize complex objects.

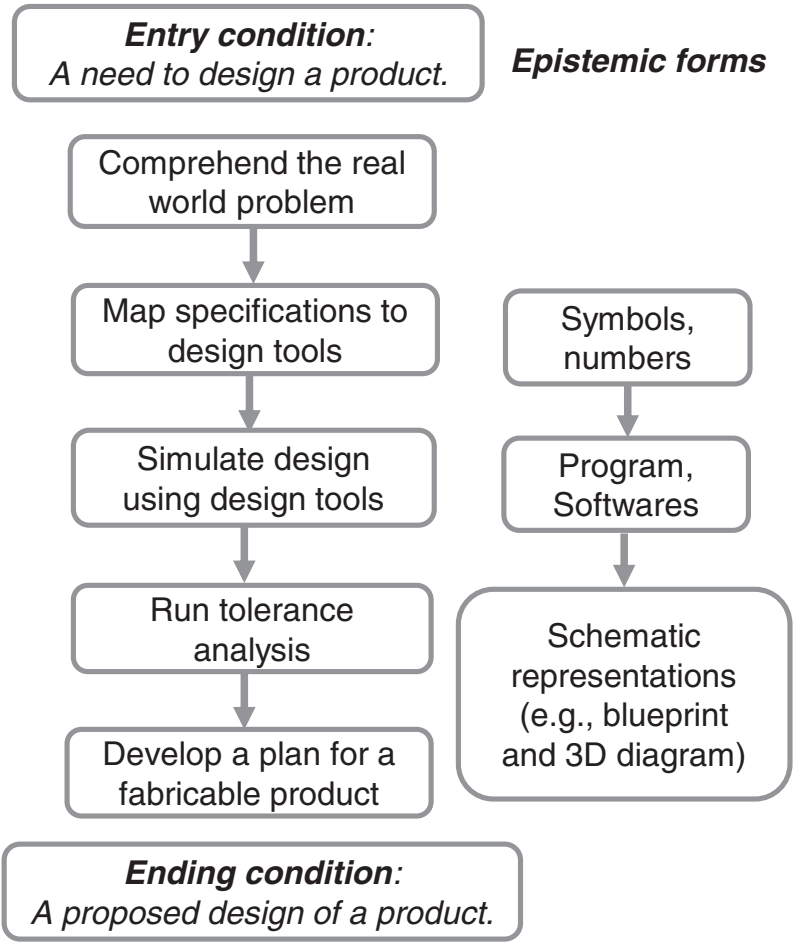

FIG. 3. Design-oriented math modeling game. While process is shown linearly, iteration commonly occurs between steps.

where somebody's not bringing up a print, bringing up a model, and looking at stuff."

Five moves were identified: (i) Comprehend the realworld problem, (ii) map the specifications to design tools, (iii) simulate the design using design tools, (iv) run tolerance analysis, (v) develop a plan for a fabricable product. When playing this game, the player starts with a real-world problem, usually involving specific requirements from customers (e.g., dimensions, mechanical properties, and optical properties). Next, these customer requirements are mapped into parameters in a digital design tool. This mapping process might involve mathematical calculations (e.g., unit conversion as a simple example). Moves two and three are usually associated with the frequent use of symbols and numbers as key epistemic forms. The next key move is to simulate the design using software design tools, which that may or may not require programming skills. Common tools include SolidWorks (computer-aided design software), ZEMAX (optical design software), or COMSOL (multiphysics simulation software). Next, a tolerance analysis is done to identify how sources of variation in specific parameters may contribute to variations in the product's overall performance. Lastly, the player needs to develop a plan for the product, and it is usually expressed in a schematic, blueprint, or a 3D diagram. Although Fig. 3 visually represents the game as a linear process, it is typically an iterative process involving refining and evaluating based on customer needs and other contextual constraints, such as costs, materials, and time.

When playing this game, several kinds of knowledge resources must be activated. First of all, it is necessary to have knowledge about the physics context and relevant theories. For example, when designing a lens system, the player needs to have a thorough understanding of geometrical optics, and to be able to apply principles (e.g., principles of refraction) learned in geometrical optics. Then, it is also critical to master the basic mathematical skills based on the need of the problem. The player also needs basic mathematical skills including arithmetic, trigonometry, and calculus. Finally, the player needs to know how particular objects and their parameters are represented within the software, because they need to translate their model into the software tool.

\section{Example of the design-oriented math modeling game (A)}

An optical engineer explained the process of starting a design project. The engineer started with a description of what the customer wants (i.e., the position of the image and other requirements for the projector). Her final goal as an optical engineer was to determine all parts of the optical design and make the design plans, which is the ending condition of the game.

"[It starts with] some specs, but then you have to design for that specific projector, like different parts of the design have to fit in it and stuff like that. Usually they [customers] know where they want the image to be; so they know the project, and they know where they want the image to be..."

"And so I figure out the rest and yeah, design the lenses. I do the mechanical drawings, just the glass parts, and then a mechanical engineer actually goes and figures out how to hold it."

Then this optical engineer talked about using a variety of tools during the design process: ZEMAX for lens design, Autodesk Inventor for mechanical drawings, and Excel for graphing, mathematical calculations, and solving systems of equations. Calculations often involve geometry, trigonometry, and arithmetic in order to determine parameters in the lens system.

"A lot of it is software skill because we use ZEMAX to design the lens, and so you have to know how to use the program to actually do what you want to do... Also we're using Inventor for $C A D$ drawings, and I had to 
learn to do that, to draw things. There's a lot of software skills that are important. I still use Excel at times."

"Lately I've been using a lot [of math] for application stuff where it's doing geometry calculations. A lot of it's just trig. A lot of it's like, 'Here's your lens, here's the angle coming out of it, here's the screen, that's a triangle.'If this has to be this distance, and this has to be this distance, what's the angle? So I do a lot of math stuff, a lot of graphing things just to see what it looks like... A lot of writing in an Excel spreadsheet to find an intersection of a line and a circle, which was harder than I thought it was going to be."

\section{Example of the design-oriented math modeling game (B)}

The episode below is from an interview with an applied technology and metrology manager who managers a group of engineers, including optical engineers, mechanical engineers, software, and electrical engineers. He briefly explained the steps of the optical design process.

"The optical designers, for example, they will take a customer specification document. I want a lens that does this, that, and the other thing. They have to create a lens design, and a tolerance analysis, and potentially a build strategy to make that lens for the customer..."

Industrial workplaces provide ample opportunities for playing design-oriented math modeling game in large part because the mission of the companies is to design and manufacture optical components and systems. The designs and the resulting products are essential. Academic researchers often engage in similar design work, and there were discussions about instrument design; however, the product is typically not the end goal for the researcher, but it is a means to advance towards an answer to a research question. In research, the knowledge generated through the design process and the use of the resulting product is of primary importance. Both examples for the analytical-numerical math modeling game (Sec. V B) represent a form of designing, but with less emphasis on creating design plans and more emphasis on understanding how the system works.

\section{Fabrication game}

It is common to design and fabricate products in industry because selling products (or design services) is how companies generate income. Prior to the fabrication stage, engineers typically meet with customers to determine design specifications. These design specifications serve as a starting point for making models and developing plans for products, which is often a blueprint or schematic. Because design activity is usually performed by engineers and fabrication activity is done by technicians (these are two separate roles within most optics companies), design and fabrication can be described as separate epistemic games, though they are linked together.

The fabrication game is shown in Fig. 4. This game is typically initiated by the need to fabricate a product and the ending condition is to generate the product and its performance report. Five moves are identified: (i) Receive and interpret blueprints, (ii) translate blueprints to G-code (a programming language for controlling machines) and do other preliminary calculation, (iii) make prototypes or products, (iv) test optical and other properties, and (v) generate a report of the test result.

In the workplaces we investigated, designs and blueprints were usually provided by engineers. Technicians used the blueprints to start the fabrication. Fabrication game requires interpretation of blueprints (involves geometry and interpreting cross sections), developing 3D mental models, and converting those models and diagrams to computer code for robotic machine tools using a programming language known as G-code. Typically, a prototype is made first and then its properties are tested (e.g., mechanical and optical properties) before making larger quantities

\section{Fabrication Game}

Knowledge base: Professional skills, such as visualization and interpretation of blueprints, and programming CNC machine using G-codes; troubleshooting skills, math skills, and communication skills.

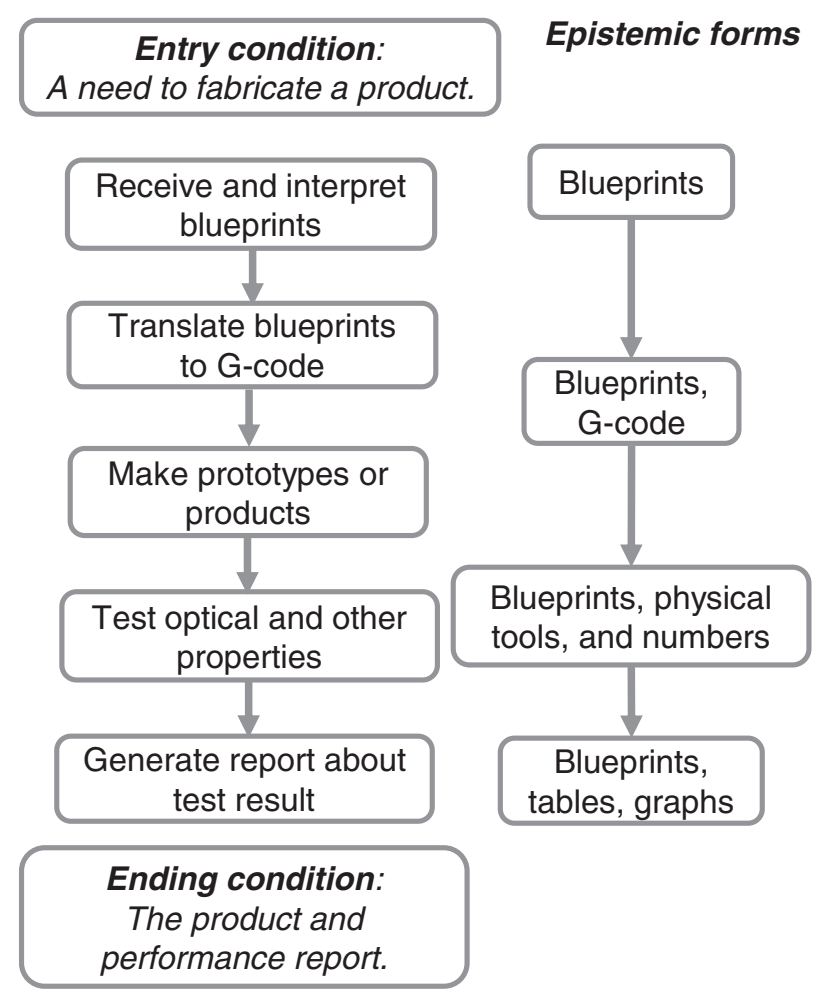

FIG. 4. Fabrication game. While process is shown linearly, iteration commonly occurs between steps. 
of the product. Manufacturing prototypes or products and testing require the ability to operate relevant machines and measurement tools. Coordinating blueprints with the manufacturing and testing processes is also important. In addition, it also involves troubleshooting skills to diagnose problems and evaluate testing results. Lastly, a report is generated summarizing the product performance based on testing results. The fabrication game ends when both products and performance reports are ready.

\section{Example of the fabrication game (A)}

One recently hired technician briefly summarized a typical day, which overviews the fabrication game. This particular quote also emphasizes the importance of testing and comparison with the customer's desired specification.

\begin{abstract}
"But right now it's just running the machine, checking the parts, recording that data so that if the customer asks for the inspection reports that it's all there. We do all our own inspections too. I'm responsible for checking the parts and logging the data. [The inspection] is on the metrology side. There's a profilometer which checks the form of the part, the radius of whatever we're cutting up. There's a white light [interferometer] which, I don't know if that's the proper name for it but it checks the surface roughness. We have to be below a certain amount of [roughness] - it measures in angstroms. So we have to be below a certain amount. Whatever the print says...there's a tolerance for it."
\end{abstract}

The technician talked about his own role in generating the inspection report for customer, including running the machine, checking parts, and recording data. Thus, the epistemic forms involved in this process are physical tools (e.g., profilometer), numbers (e.g., measured data), and diagrams (blueprints).

\section{Example of the fabrication game $(B)$}

Employees at multiple companies emphasized the importance of blue print reading. One manager, when discussing on-the-job training, said his company focused on

"Understanding what an optical print is saying, and how to read it, and what the parameters are, and things like that."

At another company, one employee elaborated on one aspect of print reading-developing a 3D mental model based on a series of $2 \mathrm{D}$ perspectives.

"When you get a standard print, you get it in a top, bottom and side view on it, which you don't get a chance to see... a 3D image of it looks like. A person who can locate a print and see a top, bottom, and a side view and visualize what that is going to look like when they're done tends to have a real big advantage in this industry."

A third interviewee described other aspects of reading and interpreting blueprints. In particular, he discussed the need for evaluating dimensions and interpreting tolerances.

"Most of our blueprints are in metric, so the technicians need to be able to evaluate the dimensions in the blueprint based on their starting point. Now, their starting point could be a block of glass, it could be a molded disk, it could be part of a component already in a sequence of things where they've got given tolerances and they need to add or subtract based on the current vs where the ideal is."

In summary, reading blueprints requires a particular set of professional skills, such as the ability to visualize and interpret diagrams, as well as fundamental mathematical skills.

\section{Example of the fabrication game $(C)$}

When describing the necessary knowledge for operating the CNC (i.e., computer numerical control) machines that shape the glass optics, one manager described helpful programming experience, such as the use of CAD-CAM software (e.g., G-code).

"If they're going to do purely machining, some level of $C A D$-CAM understanding. So, writing G-codes, what $G$-codes mean, $G$-code language, exposure to that is very important...because motion control, especially with the complex shapes, becomes more and more important."

\section{Example of the fabrication game (D)}

In this last example, another manager of technicians is explaining the importance of understanding physics and math concepts involved in the testing process. An understanding of how light behaves allows a technician to better interpret the test results, identify the underlying problems in the part, and fix the problems.

"If you go [up] from entry-level, then you become...an actual optical inspector. That's when all the lasers and equipment come in, and that's when you've really got to buckle down on the conceptual. Make sure they understand the trigonometry, because that's how the light's going to move. It's all based on how the form of that optic is made. If somewhere in the geometry of the form you're off, the optic doesn't function. Why? I need people to be able to identify where in the geometry that it's gone wrong." 


\section{E. Improving processes game}

Within industry, employees are constantly trying to improve the overall work flow and processes of their respective companies. An ideal process would produce the most amount of yield for the least amount of time and expense. To develop such improvements employees would often initiate the improving processes game as shown in Fig. 5. The entry condition for this game requires an existing process that can be improved and made more efficient. Four moves were identified: (i) analyze the root cause, (ii) design a work flow simulation or experiment, (iii) adjust parameters to optimize the process, and (iv) refine the process.

The game starts by performing root cause analysis (RCA) to identify the problems and limitations of a particular process. After identifying potential causes, computational tools are incorporated into the game to design a simulation or experiment of the improved process. Within the interviews, the most referenced choice of computational tool used for this step was MATLAB. Additionally, the tools used for this game were all computational in order to leverage the ability to perform repetitive loops of calculations faster than an individual could do them by hand. The new process is then tested by performing various optimization methods facilitated by statistical tools and optical design tools such as JMP, ZEMAX, and Code V. These optimization tools were utilized because they specialize in

\section{Improving Processes Game}

Knowledge base: STEM skill set (math and physics), such as arithmetic and optics; Communication skill set and coding skill set.

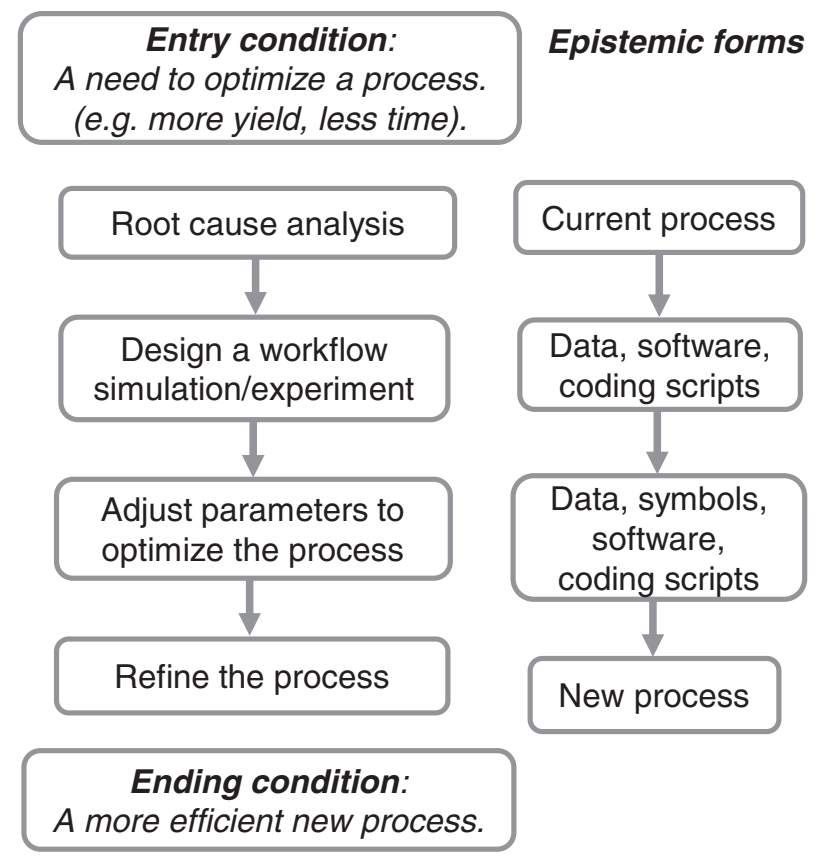

FIG. 5. Improving processes game. While process is shown linearly, iteration commonly occurs between steps. the optimization of operations when dealing with what the companies are producing. As a last step to the game, engineers make final additions and removals to the new process, resulting in the ending condition of this game which is a new and improved process.

RCA is a key move toward this game. RCA is an indepth analysis for identifying the cause of a problem in the process of troubleshooting. In science and engineering, RCA is a method of problem solving used for identifying the root cause of faults or problems [51]. The first two examples below specifically shows how RCA is used in the photonics industry.

\section{Example of the improving processes game (A)}

A manager discussed RCA in the employee training.

"It's the troubleshooting root cause discovery aspect of-because what I will do, as part of the training regiment, I will get purposefully altered optics and I'll throw it into a batch along with the good ones. Find me the bad one, then tell me why. Find the root cause, "Is it because of the surface? Is it because of the form? Is it because there's a material problem there you can identify? Is there some splay on the part? Is there a weld line in there redirecting light?" Tell me why. That's where the physics come in. Usually, once a person gets to the point where they can start discovering the root cause, then I can get in to the physics of the light and how it travels and what it does."

To identify the root cause, it requires the deep understanding of the concepts in the system. For instance, to find out the root cause of the altered optics, the employee needs to understand how light travels and how light interacts with materials. Thus, RCA often involves the conceptual math modeling game where a quick qualitative understanding of the mathematical equations comes into play. The next example emphasizes the use of standard frameworks (e.g., Ishikawa diagram or the fishbone diagram, Lean six sigma) for the RCA process in manufacturing.

\section{Example of the improving processes game $(B)$}

A project manager explained what problem-solving competencies mean in his company. For complicated problem solving, he emphasizes on structured problem solving and the use of a systematic approach to discover the root cause of a problem.

"If I change this how does it impact-what is the result of that, and then starting to piece those things together to actually see what could be causing the problem... What we're doing now, the problems are a little bit bigger, the things we're making are more complicated...we're really, really digging into kind of the hard-core, I'd say, structured problem-solving approaches. So doing 
fishbone diagrams to look at whatever, the machine, the method, man, environment...it kind of gives you a structure to lay out all the different possibilities."

Then the project manager went on to demonstrate what root cause analysis means through an example in his work environment. So instead of guessing the cause of problem in an intuitive way that may overlook some deep level problem, using a more structured process for root cause analysis drives people to analyze the problem from multiple perspectives and systematically rule out potential causes.

"And so for us, it would be like the coating chamber parts came out dirty... There's a huge amount of things that can happen to cause that...Okay. That would be like a machine issue... But if you do this properly and you think of the environment, well, what could cause parts being dirty, like an environmental perspective? Humidity can be a problem or maybe Mother Nature. They're like, 'Oh, crap. We had a power outage and there's power fluctuation.' It would force you into thinking about those things. So it's kind of a way to drive you to kind of expand your mind in a more structured way."

In addition to problem solving, the project manager also mentioned that root cause analysis plays an important role in the design of experiment. RCA provides a way to identify the impact from multiple variables and see the interaction between variables.

"DOEs(Design Of Experiment) are cool because instead of the thing I think a lot of people originally learn, where you keep all the variables the same and you only change one and see how it impacts the result, a DOE, you change multiple variables across a structured kind of experiment matrix and you can see the interactions between the different variables. So if you have something that is-if there's a root cause that has more than one input to it, that's what a DOE will find, like single variable."

\section{Example of the improving processes game $(C)$}

A manufacturing engineer explained his overall job responsibility, which involves regular interactions with technicians who fabricate parts in order to "identify gaps in their system." To achieve this goal, it is critical to conduct root cause analysis and eventually refine the process.

"Either they're teaching me how to make the parts, or I'm just working with them helping them making the parts-helping get parts out. From those [interactions] I identify gaps in their system and then refine process or add to a process."
Earlier in the interview, he specifically mentioned about the use of mathematics in his job activities, which includes creating computational tools for existing processes and designing MATLAB simulations that model current work flow. MATLAB is a very powerful programming tool in science and engineering and it integrates computation, visualization, and programming in an easy-to-use environment where problems and solutions are expressed in familiar mathematical notation.

"I was able to make a few [computational] tools that reduced processing time and gave them more information on what they're actually yielding from the process... I made a recommendation that we'd change the way that we'd flow work through ourselves. I made a MATLAB simulation out of it."

\section{Example of the improving processes game (D)}

A manager talks about the statistical tool JMP and how engineers use it to predict the efficiency and reliability of the products by designing a simulation of the production flow.

"So, when we make these products-so this is a light and it lights up-well it has to have certain properties, it has to be so much brightness, and so efficient. And we have to predict how-if we're going to make a million of them, how many of them are going to work?"

\section{F. Making meaning out of data game}

Working with data is essential in many workplace settings. In a research lab, the ability to manipulate data and develop a qualitative and quantitative understanding of data is just as important as setting up experiments and collecting data. Advancements in computing technology makes it more efficient to collect and store large amounts of data, and many industries benefit from collecting and analyzing large datasets. As one Ph.D. advisor in our study commented, "one of the key skills as a professional researcher is to have some facility with handling data on a computer and be able to visualize it, and understand what might be going wrong on the instrument." In our study, participants often reflected on workplace activities involving data processing and interpretation. The making meaning out of data game is shown in Fig. 6. The entry condition to this game involves the need to make meaning out of preexisting data. Four moves are identified: (i) prepare data in a workable format, (ii) visualize data, (iii) explore patterns, (iv) fit data with a quantitative model.

The first move to this game involves cleaning, organizing, and transforming data into a format that is easy for further analysis. A variety of representations (e.g., data formats and programming languages) and skills (e.g., writing scripts to automate repetitive steps) can be involved in this move. For example, the astrophysics student in 
Making Meaning Out of Data Game

Knowledge base: STEM skill set (math and physics), such as differential equations and optics. Working with data (extraction, analysis). Coding skill set.

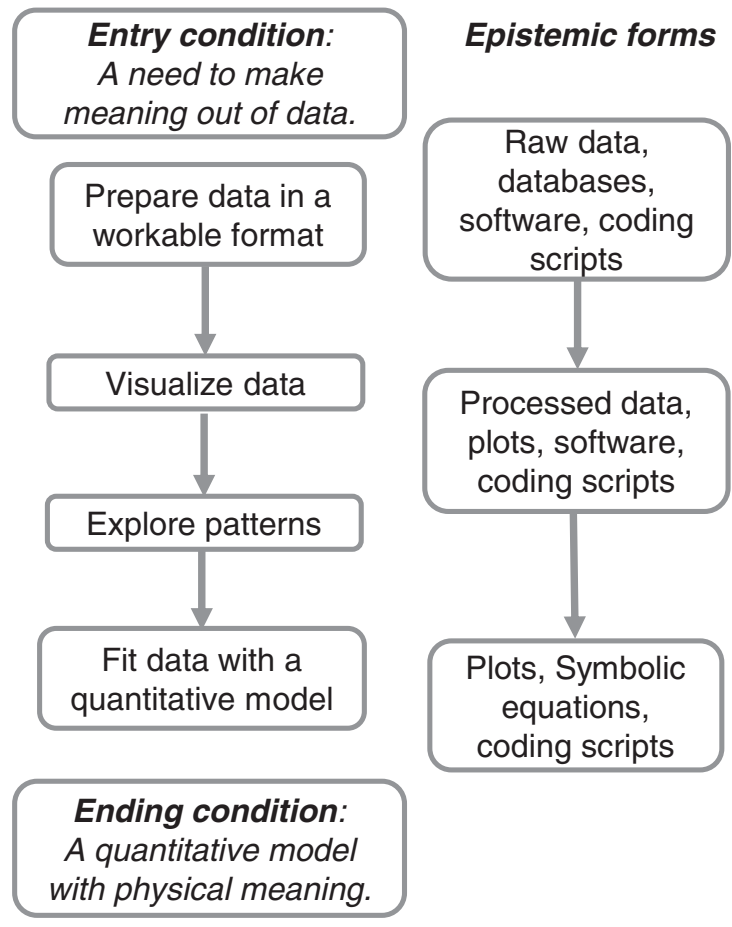

FIG. 6. Making meaning out of data game. While process is shown linearly, iteration commonly occurs between steps.

example A (below) needs to convert raw data from an instrument into a format that be viewed as molecular spectra. Some other researchers might interact with a database and extract data using SQL, a database programming language. The second move involves visualization of data through diagrams, graphs, charts, or other visual representations using computational tools, such as MATLAB, Python, and IDL. The third move involves qualitative observations about visualizations in which patterns or trends start to emerge, which could guide further analysis. In the final move, the data is fit with a quantitative model in order to develop a more accurate and mathematical description of the data.

\section{Example of the making meaning out of data game (A)}

An astrophysics Ph.D. student explained how he dealt with data in his research, where the main goal is to understand the dynamics of galaxies. After collecting a large amount of data from the telescope, the data need to be changed to a useful format. The data transformation is usually automated by programs written by the researcher or others.

"For example, when we make observations with our telescope, the data don't come ready to use. You need to go through a process which we call data reduction, which means that you need to change the format of the data. First of all, you need to understand what the format means, why do you get there, so you need to understand what the instruments did, so you understand the format. And then you may understand how to transform that data into a format you can use. So you need to write a code or use codes that other people wrote."

Then in another excerpt, the player is talking about the process of converting the data into usable visualization.

"From the telescope, they arrange the spectra in a given way into a file. But if I look at a spectra, if I try to read them, they don't look anything like what I know is a spectrum. You see what I mean? It's like, I suppose, going from binary code to an image. You look at the binary code, you just see the one zero and you say "Okay, what is that?" And then you see the image-it's [going] from here to here."

Then the student goes beyond visualization to fit the data with a quantitative model. The epistemic form moves from the original raw data, to usable data, to visualizations, to an analytic mathematical expression. The game ends with a quantitative mathematical model as well as its physical meaning.

As I said, what I can-probably what was most difficult was to make a model for the evolution of something that I was observing... So what we wanted to find out was how to model a sample of galaxies where these are found in each galaxy. So we're asking ourselves," What do we expect to see if we look at this galaxy today?" So we had to put this into an analytical form. So I had to write a function which took into account a number of things.

\section{Example of the making meaning out of data game (B)}

The following episode specifically focuses on visualizing and interpreting data. Another astrophysics researcher is describing part of the data analysis process. By following his advisor's suggestion, he starts with making plots, which is an exploratory process - making plots with everything as he explains. Making plots allows the player to visualize data, thus, it makes it easier to look for patterns or any interesting trends in the data.

"My adviser says to start with making plots... I have a table with all these columns. So he told me to make plots with everything - combination of column one with column two, column one and column ten-and then see if you find any pattern in them. If you find a pattern, that is interesting. If you don't find a pattern, that is also 
interesting [laughter]. And so he said take one plot and then understand the axis."

The researcher continued to explain how he makes sense of plots-understanding the axis, getting physical meaning of the plots, as well as reading papers when encountering difficulties.

"I look at the plots. How do I interpret it? Okay, I have on $x$ axis, let's say, brightness of a galaxy in optical wavelength... What is the physical meaning of it? It is a very difficult thing to come up with an analysis on top of plot. You develop it by reading papers. Look in the literature...So, see how they have tried to analyze that results. You can think in those lines. That's how you can start off."

Although the previous two examples highlight how making meaning out of data is undertaken by academic researchers, it is relevant to industry as well. In interviews with employers outside of optics and photonics we have encountered multiple companies prioritizing workplace training in data science and data visualizations, typically to improve efficiency of processes and develop business strategies informed by data.

\section{IMPLICATIONS FOR PER}

While the previous section detailed six different epistemic games prevalent in both Ph.D. research labs and photonics workplaces, we now look across the findings in order to comment on broader implications for physics education research and teaching.

\section{A. Goals, tools, and representations in workplace problem solving}

Because this study extends physics education research on mathematical problem solving into academic and industrial profession workplaces, such as research labs and optics and photonics companies, we identified a breadth of practices that should count as "doing math in physics." Previous research on math use in undergraduate physics curriculum mostly studied undergraduate-level homework problems [17]. However, the problems investigated by researchers, engineers, and technicians in professional workplaces, go far beyond textbook word problems. Problem types varied from a simple conceptual problem (i.e., explain how a thin lens works), troubleshooting problems, design problems, and more. These problems also cover a broad spectrum of mathematical topics, from basic arithmetic to advanced computational skills. The goals, tools, and context strongly affects how math is done.

Considering goals for mathematics use, a researcher in pursuit of understanding may engage in conceptual math modeling or making meaning from data; however, an engineer designing, making, or improving a real product may be more likely to engage in design-oriented math modeling, the fabrication game, or the improving processes game. All of these goal-oriented activities are typical of physics-related careers and do occur in both academic and industry though they may differ in prevalence. It is critical to study mathematical activities that are directed at understanding the physical world as well as those that design and make new things, which is valued in experimental and applied physics research as well as engineering.

In addition to recognizing diverse goals of mathematical activities, workplaces also reveal a diverse set of mathematical tools and representations. For example, the design-oriented math modeling game involved calculation tools (e.g., Excel), data visualization tools (e.g., MATLAB), and design tools (e.g., SolidWorks, ZEMAX), each of which has mathematics embedded in new representations such as coding scripts, 3D CAD files, and computer-generated visualizations and animations. Learning how to coordinate mathematical knowledge (e.g., trigonometry or geometry) with various tools is also an important skill in industrial workplaces. For example, in order to design a lens system, one needs to apply basic geometry when drawing a ray diagram and to be able to do theoretical calculations for certain distances (e.g., focal length) or angles on paper or with calculation tools such as Excel.

\section{B. Comparing views on modeling as a process}

Modeling and model-based reasoning has been a focus within the PER community for decades. Our study extends frameworks for describing modeling as a problem-solving process. There have been few models in PER to describe problem solving outside of classroom settings. Our study specifically identified and categorized three mathematical modeling games in both academic and industrial workplaces. Our epistemic games clearly demonstrate how mathematical modeling is affected by goals, which includes developing a conceptual or qualitative understanding of a physical phenomenon, finding a quantitative solution to a complex real-world problem, and designing a physical product.

Redish's "math use in physics" four-step modeling process provided a guideline for thinking about physics problem solving in general and it primarily focuses on obtaining a conceptual or qualitative understanding, although sometimes accompanied by a numerical solution [22]. Then Hestenes and Halloun developed a four-step process to describe mathematical modeling in physics, which includes model description, formulation, ramification, and validation [52]. Later on, Hestenes defined a set of modeling games for the purpose of teaching aspects of modeling to students, such as model building, model validation, and model deployment to explain, to predict, and to describe physical phenomena [53]. Hestenes' modeling games described how the scientific community 
progresses using examples from the history of science (e.g., Einstein's relativity), which often took many years for the community to play [53]. Hestenes' modeling games were not formal epistemic games in the sense used by Collins and Ferguson [44], but bear some similarities. Hestenes' games primarily revolved around understanding the natural world, but ignored other forms of technical work (e.g., design, improving process) done in careers common for physics majors. The epistemic games identified in Tuminaro and Redish's work nicely capture most introductory physics problem solving [17].

Other descriptions of the modeling process have been developed for a laboratory education context. The Investigative Science Learning Environment (ISLE) curriculum emphasizes modeling in introductory-level laboratory courses through a learning cycle: making observations, identifying patterns, creating explanations, articulating assumptions, making predictions, testing predictions, and revising models and experiments [54]. More recently, a framework for modeling in upper-division physics labs additionally included constructing models of the measurement tools and several pathways for revisions of the models and apparatus [55]. While these other descriptions of modeling are applicable in a contextually rich learning environment (e.g., a lab course), they do not capture the diversity of goals present in the different math modeling epistemic games. The lab-based modeling activities prioritize understanding a system and quantitative comparison between data and models, which is most similar to the analytical-numerical modeling game that centers on making accurate quantitative predictions. Also, the lab modeling framework did not discuss modeling for design.

\section{Challenges in applying epistemic games framework}

While epistemic games framework is powerful for characterizing problem-solving strategies, we found it challenging to directly apply this framework to activities in complex professional workplaces for several reasons: (i) epistemic games occur on a variety of scales, (ii) context and constraints needs to be more generally considered, and (iii) the games cannot just be a sequence of moves, but require coordination between moves, representations, and tool use.

Regarding the scale of epistemic games, it was not uncommon to identify one epistemic game as a subgame within a larger game. This happens whenever one larger goal is divided up into several smaller subgoals, each of which represents a shift in epistemic games. For example, the conceptual math modeling game is a subgame of the analytical-numerical math modeling game. The goal of the conceptual math modeling game is to obtain a conceptual understanding of a physical system, which is also an important intermediate goal in the analytical-numerical math modeling game.
The original framing of constraints within epistemic games (as part of context) is often limited to the rules imposed by the player in order to complete a game (e.g., distinctness is one of the constraints in the list-making game) [44]. However, in workplaces constraints may be imposed by a customer, machine, or a limitation in resources or time. For example, in the design-oriented math modeling game, constraints may arise from customer specifications as well as those imposed by material properties or equipment limitations. These constraints would affect both the design process and tolerance analysis.

Finally, epistemic games require the coordination of goals, moves, various tools, representations, and knowledge base. Coordination is especially important as with each move the representations, constraints, and other contextual factors (e.g., motivation, time, cost, material limitations, and tools available) might change. One important feature of our epistemic games is that they capture the transition of epistemic forms as the game progresses.

Although these comments might be hinted at in prior work, they are especially salient for complex workplace tasks.

\section{IMPLICATIONS FOR TEACHING}

Implications for teaching fall into three categories: identification of epistemic games prevalent in workplaces, which are less common in coursework; using epistemic games as an activity generation tool; and using epistemic games to make problem-solving approaches more explicit for students.

\section{A. Instruction with diverse epistemic games}

Within both workplaces, two epistemic games are particularly prevalent: conceptual and design-oriented math modeling games. The ability to develop quick conceptual understanding of a physical system or phenomenon is critical in professional settings. It is worth noting that the conceptual math modeling game is substantially different from many undergraduate-level physics homework problems in that it emphasizes building and exploring mathematical models. Model building, which includes identifying quantities of interest and simplifying assumptions, is often skipped when solving pre-idealized back-ofthe-chapter problems. Similarly, conceptual math models are used to explore trends through symbolic manipulation and interpretation of results, which is a different end goal than many homework problems. Regarding the designoriented modeling game, both workplaces provide ample opportunities for the design of products: within industry, it is often the design of a product based upon customers' needs; within academia, it could be design of an instrument for an experiment.

In the industry workplace, three epistemic games are particularly prevalent and important. These are designoriented math modeling, fabrication, and improving 
processes games; however physics courses rarely include problems involving design, fabrication, and improvement or optimization. As the findings show, these are physicsintensive, mathematically rich epistemic games that employ diverse representations. Because many students go on to professional work involving these kinds of problems it seems wise to provide opportunities for students in their courses.

Further, five of the six games integrated computational approaches in a significant way, the exception being the conceptual math modeling game in Sec. VA, which emphasized symbolic equations as a conceptual relationship and exploring trends by making meaning of the symbolic equations. The ubiquity of computation in the five games emphasizes that computation should be ubiquitous in the curriculum if we intend to provide students with problem-solving abilities that are applicable to modern problems. Computation does not always mean programming as demonstrated by several of the games that employed other tools such as Excel to analyze and visualize data. Further, computation is sometimes connected to physical actions such as with programming robotic fabrication tools.

\section{B. Epistemic games for inspiring curriculum development}

The framework for epistemic games can be used to construct more diverse problem-solving activities for students. For instance, using a micro electromechanical system (MEMS) accelerometer as the central object of inquiry [56-58], students could have an initial goal to develop a simple conceptual math model, perhaps a massspring system with a capacitor, that explains how the sensor creates a response proportional to the acceleration, which can be measured. They could then explore relationships between particular aspects of the design (e.g., mass or stiffness of the flexible part) and performance characteristics (e.g., the sensitivity of the accelerometer). As an analytical-computational modeling exercise, students could extend the conceptual model by inputting more realistic material parameters, dimensions, and actual device geometries (replacing a spring with a flexing beam) to get an accurate quantitative relationship between acceleration and capacitance. Finally, as a design task, students could be given a set of target requirements, e.g., device size, acceleration range, sensitivity, and be expected to optimize device size and materials to accomplish this task. In a more projectoriented, or technology focused course, a design-oriented modeling activity could also integrate software tools for more sophisticated geometries for the accelerometer test mass and capacitive sensors. By changing the end goals, initial problem state, and tools, the same content (e.g., a MEMS accelerometers) can facilitate a range of epistemic games centered around modeling. It may be that some games, such as design-oriented games, require an extended amount of time because of the open-ended outcomes, specialized software tools, and likelihood of iteration. In the workplace, such games could take place across multiple days.

\section{Making problem-solving strategies explicit}

The six epistemic games highlighted in the results (Sec. V) may be a useful guide for problem-solving instruction. The original intent of Collins and Ferguson [44] was to provide an explicit description of a wide range of inquiry processes in fields like science and history, which also illustrated the applicability to everyday situations. Epistemic games go beyond a fixed set of generic steps (e.g., identify, plan, execute, reflect) and provide a link between the individual moves, the starting and ending conditions, and the goals of the activity. Within our re-interpreted framework for epistemic games, we also highlight the varying representation and tool changes throughout each game, which further makes problemsolving processes and strategies more explicit. Through the explicit identification of games, it is possible to guide students and make them more aware of their own problemsolving approaches, but in ways that can be more targeted to the nature of a specific problem (e.g., a design problem).

In summary, workplace contexts, both in academic research and industry offer insights into mathematical problem-solving practices that integrate math and physics in diverse and sophisticated ways. Through the lens of epistemic games, we have identified common games and provided examples. We have also explored how these findings enhance our understanding of the relationship between math and physics as well as provide insights that may inspire novel pedagogical approaches. As physics departments consider how they integrate career preparation within the physics curriculum, these professionally relevant epistemic games provide one means for more closely linking physics coursework with professional practice.

\section{ACKNOWLEDGMENTS}

The authors acknowledge MacKenzie Stetzer for his helpful feedback on an earlier version of this manuscript. This work is supported by NSF DGE-1432578, DGE1561493, and REU-1359262. 
[1] K. P. Dabney, R. H. Tai, J. T. Almarode, J. L. Miller-Friedmann, G. Sonnert, P. M. Sadler, and Z. Hazari, Out-ofschool time science activities and association with career interest in STEM, Int. J. Sci. Educ. Part B 2, 63 (2012).

[2] A. Godwin, G. Potvin, Z. Hazari, and R. Lock, Identity, critical agency, and engineering: An affective model for predicting engineering as a career choice, J. Eng. Educ. 105, 312 (2016).

[3] Z. Hazari, G. Potvin, R. H. Tai, and J. Almarode, For the love of learning science: Connecting learning orientation and career productivity in physics and chemistry, Phys. Rev. ST Phys. Educ. Res. 6, 010107 (2010).

[4] H. B. Carlone and A. Johnson, Understanding the science experiences of successful women of color: Science identity as an analytic lens, J. Res. Sci. Teach. 44, 1187 (2007).

[5] K. Rosa and F. Moore Mensah, Educational pathways of Black women physicists: Stories of experiencing and overcoming obstacles in life, Phys. Rev. Phys. Educ. Res. 12, 020113 (2016).

[6] D. B. Bills, Credentials, signals, and screens: Explaining the relationship between schooling and job assignment, Rev. Educ. Res. 73, 441 (2003).

[7] J. Lave, Cognition in Practice: Mind, Mathematics and Culture in Everyday Life (Cambridge University Press, Cambridge, England; New York, 1988).

[8] National Science Foundation, Research on Learning in Formal and Informal Settings (DRL), https://www.nsf.gov/ ehr/drl/about.jsp.

[9] P. Mulvey and J. Pold, Physics Bachelors: Initial Employment, Tech. Rep. (American Institute of Physics, New York, 2017).

[10] J. Williams and G. Wake, Black boxes in workplace mathematics, Educ. Studies Math. 64, 317 (2007).

[11] G. Wake, Making sense of and with mathematics: the interface between academic mathematics and mathematics in practice, Educ. Studies Math. 86, 271 (2014).

[12] D. Jonassen, J. Strobel, and C. B. Lee, Everyday problem solving in engineering: Lessons for engineering educators, J. Eng. Educ. 95, 139 (2006).

[13] A. E. Leak, S. L. Rothwell, J. Olivera, B. Zwickl, J. Vosburg, and K. N. Martin, Examining problem solving in physics-intensive Ph.D. research, Phys. Rev. Phys. Educ. Res. 13, 020101 (2017).

[14] E. F. Redish and E. Kuo, Language of physics, language of math: Disciplinary culture and dynamic epistemology, Sci. Educ. 24, 561 (2015).

[15] E. P. Wigner, The unreasonable effectiveness of mathematics in the natural sciences, Commun. Pure Appl. Math. 13, 1 (1960).

[16] J. L. Docktor and J. P. Mestre, Synthesis of disciplinebased education research in physics, Phys. Rev. ST Phys. Educ. Res. 10, 020119 (2014).

[17] J. Tuminaro and E. F. Redish, Elements of a cognitive model of physics problem solving: Epistemic games, Phys. Rev. ST Phys. Educ. Res. 3, 020101 (2007).

[18] J. R. Hayes, The Complete Problem Solver (Routledge, London, 2013).

[19] D. P. Maloney, An overview of physics education research on problem solving, Getting started in PER (2011), Vol. 2, https://www.per-central.org/items/detail.cfm?ID=11457.
[20] D. H. Jonassen, Toward a design theory of problem solving, Educ. Technol. Res. Dev. 48, 63 (2000).

[21] W. K. Adams and C.E. Wieman, Analyzing the many skills involved in solving complex physics problems, Am. J. Phys. 83, 459 (2015).

[22] E. F. Redish, Problem solving and the use of math in physics courses (2006), https://arxiv.org/ftp/physics/ papers/0608/0608268.pdf.

[23] J. Aguirre and G. Erickson, Students' conceptions about the vector characteristics of three physics concepts, J. Res. Sci. Teach. 21, 439 (1984).

[24] S. Flores, S. E. Kanim, and C. H. Kautz, Student use of vectors in introductory mechanics, Am. J. Phys. 72, 460 (2004).

[25] P. S. Shaffer and L. C. McDermott, A research-based approach to improving student understanding of the vector nature of kinematical concepts, Am. J. Phys. 73, 921 (2005).

[26] E. C. Sayre and M. C. Wittmann, Plasticity of intermediate mechanics students coordinate system choice, Phys. Rev. ST Phys. Educ. Res. 4, 020105 (2008).

[27] D.-H. Nguyen and N. S. Rebello, Students' difficulties in transfer of problem solving across representations, AIP Conf. Proc. 1179, 221 (2009).

[28] C. Triantafillou and D. Potari, Mathematical practices in a technological workplace: the role of tools, Educ. Studies Math. 74, 275 (2010).

[29] Z. Magajna and J. Monaghan, Advanced mathematical thinking in a technological workplace, Educ. Studies Math. 52, 101 (2003).

[30] T. Wedege, Numeracy as a basic qualification in semiskilled jobs, For the Learning of Mathematics 22, 23 (2002).

[31] J. M. Wing, Computational thinkings influence on research and education for all, Italian J. Educ. Technol. 25, 7 (2017).

[32] D. Weintrop, E. Beheshti, M. Horn, K. Orton, K. Jona, L. Trouille, and U. Wilensky, Defining computational thinking for mathematics and science classrooms, J. Sci. Educ. Technol. 25, 127 (2016).

[33] K. Brennan and M. Resnick, New frameworks for studying and assessing the development of computational thinking, in Proceedings of the 2012 annual meeting of the American Educational Research Association, Vancouver, Canada (2012), pp. 1-25.

[34] M. D. Caballero, Computation across the curriculum: What skills are needed? arXiv:1507.00533.

[35] J. M. Aiken, M. D. Caballero, S. S. Douglas, J. B. Burk, E. M. Scanlon, B. D. Thoms, and M. F. Schatz, Understanding student computational thinking with computational modeling, AIP Conf. Proc. 1513, 46 (2012).

[36] B. L. Sherin, How students understand physics equations, Cognit. Instr. 19, 479 (2001).

[37] T. J. Bing and E. F. Redish, The cognitive blending of mathematics and physics knowledge, AIP Conf. Proc. 883, 26 (2007).

[38] D. Hu and N.S. Rebello, Using conceptual blending to describe how students use mathematical integrals in physics, Phys. Rev. ST Phys. Educ. Res. 9, 020118 (2013).

[39] T. J. Bing and E. F. Redish, Analyzing problem solving using math in physics: Epistemological framing via warrants, Phys. Rev. ST Phys. Educ. Res. 5, 020108 (2009). 
[40] A. Gupta and A. Elby, Beyond epistemological deficits: Dynamic explanations of engineering students difficulties with mathematical sense-making, Int. J. Sci. Educ. 33, 2463 (2011).

[41] G. Fauconnier and M. Turner, Conceptual integration networks, Cogn. Sci. 22, 133 (1998).

[42] Personal Epistemology in the Classroom: Theory, Research, and Implications for Practice, edited by L. D. Bendixen and F. C. Feucht (Cambridge University Press, Cambridge, England; New York, 2010).

[43] D. Hu and N. S. Rebello, Shifting college students epistemological framing using hypothetical debate problems, Phys. Rev. ST Phys. Educ. Res. 10, 010117 (2014).

[44] A. Collins and W. Ferguson, Epistemic forms and epistemic games: Structures and strategies to guide inquiry, Educ. Psychol. 28, 25 (1993).

[45] R. R. Bajracharya and J. R. Thompson, Analytical derivation: An epistemic game for solving mathematically based physics problems, Phys. Rev. Phys. Educ. Res. 12, 010124 (2016).

[46] E. Gire, D.-H. Nguyen, and N. S. Rebello, Characterizing students' use of graphs in introductory physics with a graphical analysis, in Proceedings of the 2011 Annual Meeting of the National Association of Research in Science Teaching, Orlando, FL (2011), p. 18.

[47] Y. Chen, P. W. Irving, and E. C. Sayre, Epistemic game for answer making in learning about hydrostatics, Phys. Rev. ST Phys. Educ. Res. 9, 010108 (2013).

[48] H. Sevian and S. Couture, Epistemic games in substance characterization, Chem. Educ. Res. Pract. 19, 1029 (2018).
[49] F. T. Igira and J. Gregory, Cultural historical activity theory, in Handbook of Research on Contemporary Theoretical Models in Information Systems [Faraja Teddy Igira (University of Oslo, Norway) and Judith Gregory (Institute of Design, USA), 2009], pp. 434-454.

[50] A.H. Schoenfeld, Learning to think mathematically: Problem solving, metacognition, and sense making in mathematics (Reprint), J. Educ. 196, 1 (2017).

[51] P.F. Wilson, Root Cause Analysis: A Tool for Total Quality Management (ASQ Quality Press, Milwaukee, WI, 1993).

[52] D. Hestenes, Toward a modeling theory of physics instruction, Am. J. Phys. 55, 440 (1987).

[53] D. Hestenes, Modeling games in the Newtonian World, Am. J. Phys. 60, 732 (1992).

[54] E. Etkina and A. Van Heuvelen, Investigative Science Learning Environment (American Association of Physics Teachers, College Park, MD, 2007), Vol. 1, p. 48.

[55] B. M. Zwickl, D. Hu, N. Finkelstein, and H. J. Lewandowski, Model-based reasoning in the physics laboratory: Framework and initial results, Phys. Rev. ST Phys. Educ. Res. 11, 020113 (2015).

[56] C. L. Countryman, Familiarizing students with the basics of a smartphone's internal sensors, Phys. Teach. 52, 557 (2014).

[57] A. A. Gallitto and L. Lupo, A mechanical model of the smartphones accelerometer, Phys. Educ. 50, 646 (2015).

[58] A. Beliveau, G. T. Spencer, K. A. Thomas, and S. L. Roberson, Evaluation of MEMS capacitive accelerometers, IEEE Design Test Comput. 16, 48 (1999). 